\title{
The Life Quality of Adolescents with Special Needs Depending on Degree of Disease: Psychological Support of the Family
}

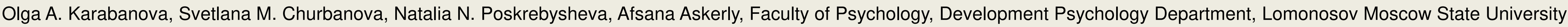
and Ekaterina S. Voroshilova, National Medical Research Center of Endocrinology, Moscow, Russia

1. Introduction

The models of psychological support of families in the United States and Europe are founded on interdisciplinary assessments to study the needs of families with special needs children and adolescents based on comparison of sociodemographic level, socioeconomic level, life cycle of family, age and gender of the child, educational context, degree of disease severity (Bailey \& Simeonson, 1988; Dunst et al., 2002; Felizardo \& Ribeiro, 2015).

\section{Methods}

5 adolescents with diabetes mellitus type aged 12-17 years (patients of National Medical Research Center of Endocrinology, Ministry of Healthcare of the Russian Federation) and 36 parents of those adolescents participated in this study. The diabetic module of PedsQL ${ }^{\mathrm{TM}}$ adapted from the original version (Varni et al., 2003) was used for adolescents and parents.

\section{The implementation of additional} interdisciplinary tools to assess the Russian sample, e.g. sociodemographic questionnaires and the Family Needs Survey adapted from the original version (Bailey \& Simeonson, 1988) will help clarify the wide range of needs of parents in psychological information.

\section{Results 1}

The results of this investigation show that the presence of initial manifestations of complications has no significant impact on the life quality of adolescents with type 1 diabetes and their parents $(r=0,6 ; \quad p<0,05)$, but significantly decreases with the severity of the disease.

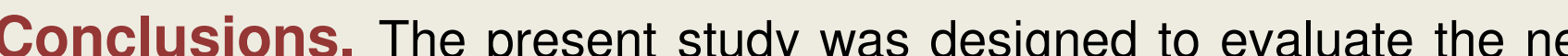

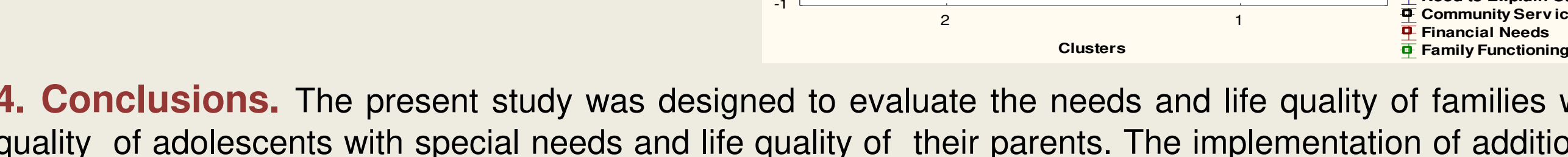
the wide range of needs of parents

varying degrees of disease severity. information on child development $(52,6 \%)$.

\section{Table 1. Distribution of the relative frequencies of the subscale «Information Needs» ${ }^{[1]}$}

\begin{tabular}{|c|c|c|c|}
\hline \multirow[t]{2}{*}{ Information Needs } & I do not need & I'm not sure & I need \\
\hline & $\%$ & $\%$ & $\%$ \\
\hline 1. Need for information about problems you may have & 10,5 & 26,3 & 63,2 \\
\hline 2. Need for information on how to deal with child's behavior & 21,1 & 10,5 & 68,4 \\
\hline 3. Need for information on how to teach my child & 26,3 & 15,8 & 57,9 \\
\hline 4. Need for information on how to play/talk with my child & 31,6 & 26,3 & 42,1 \\
\hline 5. Need for information on child development & 15,8 & 31,6 & 52,6 \\
\hline 6. Need for information about services that the child may have in the present & 15,8 & 10,5 & 73,7 \\
\hline 7. Need for information about services that the child can benefit in the future & 10,5 & 15,8 & 73,7 \\
\hline
\end{tabular}

Table 1, related to the Sub-scale «Information Needs», is the area of greatest need. The most mentioned items are: the information needs about services

that the child may have in the present and the information about services that the child can benefit in the future (both with $73,7 \%$ ); followed by information on to deal with child's behavior (68,4\%) and information about problems (63,2\%); followed by information on how to teach the child (57,9 \%) and

Table 2. Distribution of relative frequencies of the subscale «Social Support Needs»

\begin{tabular}{|c|c|c|c|}
\hline \multirow[t]{2}{*}{ Social Support Needs } & I do not need & I'm not sure & I need \\
\hline & $\%$ & $\%$ & $\%$ \\
\hline 10. Need of meeting and support of other parents of children with similar problems & 26,3 & 26,3 & 47,4 \\
\hline 11. Need to have more time to talk with a child's teacher or therapist & 31,6 & 36,8 & 31,6 \\
\hline $\begin{array}{l}\text { 12. Need of regular meetings with a counselor (psychologist, social worker) to talk } \\
\text { about problems }\end{array}$ & 31,6 & 21,1 & 47,4 \\
\hline $\begin{array}{l}\text { 14. Need for reading materials about other parents who have a child with similar } \\
\text { problems }\end{array}$ & 31,6 & 36,8 & 31,6 \\
\hline
\end{tabular}

In relation to the results of the «Social Support Needs» Sub-scale (Table 2), 47,4\% mothers need to find and support of other parents of children with similar problems and need of regular meetings with a counselor (psychologist, social worker) to talk about problems, following the needs of having more time to talk with a child's teacher or therapist $(31,6 \%)$ and having materials about other parents who have a child with similar problems. The results reveals that the most felt needs of mothers are in the area of information about the child's problems in the present and the future on child development, information on how to teach the child, followed by the needs of social support.
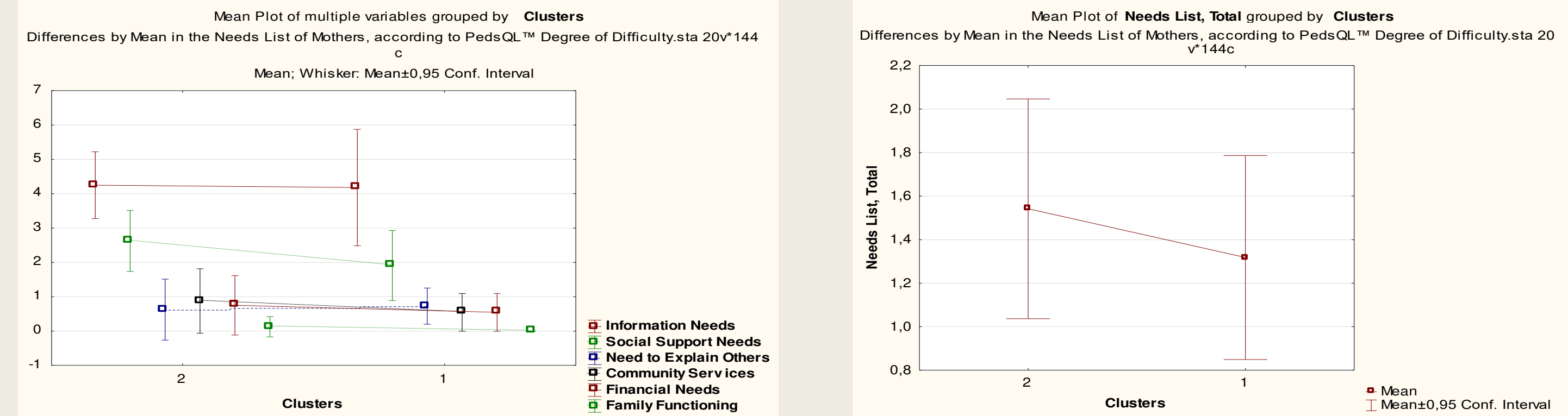

Mean Plots 1 and 2 identify the results of the 19 mothers' needs according to PedsQL ${ }^{\mathrm{TM}}$ degree of difficulty. As we can see, mothers of children with large degree of difficulty (Cluster 2) reveal more needs list than parents of children with othe degree of disease $(0,95$ Confidence Interval). 